This is the peer reviewed version of the following article: Ong, C. W., Roberts, R., Arthur, C. A., Woodman, T. and Akehurst, S. (2016), The Leader Ship Is Sinking: A Temporal Investigation of Narcissistic Leadership. Journal of Personality, 84: 237-247. doi: 10.1111/jopy.12155, which has been published in final form at http://onlinelibrary.wiley.com/doi/10.1111/jopy.12155/full. This article may be used for noncommercial purposes in accordance With Wiley Terms and Conditions for self-archiving. 
The Leader Ship is Sinking: A Temporal Investigation of Narcissistic Leadership Chin Wei Ong, Ross Roberts, Calum A. Arthur, Tim Woodman and Sally Akehurst

\author{
Author Note
}

Chin Wei Ong, Ross Roberts, and Tim Woodman, Institute for the Psychology of Elite Performance, School of Sport Health and Exercise Sciences, Bangor University; Calum A. Arthur, School of Sport, University of Stirling; Sally Akehurst, Sport, Outdoor and Exercise Science, College of Life and Natural Sciences, University of Derby.

Correspondence concerning this article should be addressed to Chin Wei Ong, Institute for the Psychology of Elite Performance, School of Sport Health and Exercise Sciences, Bangor University, Bangor, Gwynedd LL57 2PZ, United Kingdom.

Email: cw.ong@bangor.ac.uk 


\begin{abstract}
Objectives. Individuals higher in narcissism have leader emergent tendencies. The characteristics of their personality suggest, however, that their leadership qualities will decrease over time as a function of group acquaintance. We present data from two studies that provide the first empirical support for this theoretical position within a transformational leadership framework. Methods. In Study $1(n=112)$ we tested narcissistic leadership qualities in groups of unacquainted individuals over a 12-week period. In Study $2(n=152)$ we adopted the same protocol with groups of acquainted individuals. Results. In Study 1, narcissism was positively associated with peer-rated leadership during initial group formation but not later. In Study 2, narcissism was not significantly associated with peer-rated leadership during initial group formation and was negatively associated with peer-rated leadership later. In Study 1, transformational leadership mediated the relationship between narcissism and leadership initially but not later on. In Study 2, transformational leadership failed to mediate the relationship between narcissism and leadership throughout the study. Conclusions. Despite enjoying a honeymoon period of leadership, the appeal and attractiveness of the narcissistic leader rapidly wanes. This decline is explained in part by their changing transformational leadership qualities.
\end{abstract}

Keywords: transformational leadership, narcissism, time, group acquaintance, social relations model 
The Leader Ship is Sinking: A Temporal Investigation of Narcissistic Leadership

Relationships with narcissistic leaders can be a paradoxical experience, much like eating chocolate cake (Campbell, 2005; Campbell, Hoffman, Campbell, \& Marchisio, 2011). The first bite of a chocolate cake is usually rich in flavor and texture, and extremely gratifying. After a while, however, the richness of this flavor makes one feel increasingly nauseous. Being led by a narcissist ${ }^{1}$ could be a similar experience: Narcissists might initially be perceived as effective leaders, but these positive perceptions may decrease over time. Originally developed to explain romantic relationships with narcissistic individuals, the Chocolate Cake Model (Campbell, 2005) has since been applied to describe the relationships between narcissistic leaders and their followers (Campbell et al., 2011).

Although the chocolate cake model is applicable to the temporal effect of narcissistic leadership, this effect remains complex because of the dyadic and dynamic nature of leadership (Dansereau et al., 1995; Foti, Knee, \& Backert, 2008). Thus, understanding the dynamic and complex nature of the relationship between narcissism and leadership requires investigations that move beyond the simplistic position of examining whether narcissists make "good" or "bad" leaders. However, despite repeated calls (e.g., Rosenthal \& Pittinsky, 2006), there is currently no direct test of the temporal relationship between narcissism and leadership in the literature and no theoretical consideration of the role of transformational leadership within that temporal relationship. We aim to test the temporal component of narcissistic leadership with a view to examining whether being led by people higher in narcissism is akin to eating chocolate cake. In providing the first empirical test of this theoretical position, we also present and explore a possible explanatory mechanism of this effect.

\section{Narcissism and leadership}


The notion that narcissists have traits that lead followers to perceive them as leaders has been well-documented in the literature (e.g., Rosenthal \& Pittinsky, 2006). Selfregulatory models (Campbell, Brunell, \& Finkel, 2006; Morf \& Rhodewalt, 2001) describe narcissists as individuals with positive, inflated, and predominantly agentic self-views who employ self-regulatory strategies in order to maintain or enhance these self-views. Thus, narcissists would be expected actively to seek out positions of leadership, because such positions might serve to promote their self-enhancement (Campbell \& Campbell, 2009). From the perspective of the follower, narcissists seem to possess some of the requisite traits for effective leadership. For example, narcissists' extraverted disposition (Bradlee \& Emmons, 1992) allows them to be socially skilled (Oltmanns, Friedman, Fiedler, \& Turkheimer, 2004) and appear likable (Paulhus, 1998). Beyond extraversion, narcissists are also charismatic (Khoo \& Burch, 2008), perform well in public tasks and difficult situations (Roberts, Callow, Hardy, Woodman, \& Thomas, 2010; Roberts, Woodman, Hardy, Davis, \& Wallace, 2013; Wallace \& Baumeister, 2002; Woodman, Roberts, Hardy, Callow, \& Rogers, 2011), and exude an aura of confidence and dominance (Bradlee \& Emmons, 1992; Hogan, Curphy, \& Hogan, 1994). Furthermore, many illustrious positions of leadership (e.g., the US presidency) have been occupied by individuals rated higher in narcissism (e.g., Deluga, 1997; Rosenthal \& Pittinsky, 2006; Watts et al., 2013). In summary, individuals higher in narcissism seem to possess traits that predispose followers to perceive them as effective leaders.

\section{Is narcissistic leadership durable?}

Despite their possession of seemingly effective leadership characteristics, narcissists are often rated negatively on their leadership qualities (e.g., Blair, Hoffman, \& Helland, 2008; Judge, LePine, \& Rich, 2006). One potential explanation for this paradox is the way that leadership has been conceptualized in the literature. That is, leadership has typically been 
defined and measured in two distinct ways: leadership emergence and leadership effectiveness. Leadership emergence is achieved by exercising influence or attaining high social status in a group of strangers. Contrastingly, leadership effectiveness is achieved by judgments of one's performance as a leader (Hogan \& Kaiser, 2005). Thus, leader emergence and leader effectiveness are conceptually distinct and occur at distinct temporal phases, with leader emergence preceding leadership effectiveness. Despite the vast potential influence of temporality on a multitude of leadership behaviors and outcomes (see Shamir, 2011), there is a surprising dearth of consideration and evidence for the importance of temporality in leadership research (Bluedorn \& Jaussi, 2008; Shamir, 2011).

The issue of temporality (or lack thereof) is equally evident when considering narcissistic characteristics and leadership. Indeed, many of the traits that propel narcissists into positions of leadership have been posited to be the same as those that precipitate their eventual downfall (Rosenthal \& Pittinsky, 2006). Narcissists at limited acquaintance might initially be perceived favorably as leaders because they are more extraverted (Brunell, Gentry, Campbell, Hoffman, Kuhnert, \& DeMarree, 2008). Individuals high in extraversion possess confidence and strong social skills, which are essential for effective social interaction in leadership (e.g., Judge, Bono, Ilies, \& Gerhardt, 2002). The initial attractiveness of narcissists for leadership positions extends well beyond extraversion, however. Indeed, narcissists are also known to make better first impressions (Back et al., 2010; Carlson, Vazire, \& Oltmanns, 2011; Nevicka, Ten Velden, De Hoogh, \& Van Vianen, 2011; Paulhus, 1998), which likely contribute to their tendency to emerge as leaders, particularly during zero-acquaintance situations (Brunell, et al., 2008; Nevicka, De Hoogh, Van Vianen, Beersma, \& McIlwain, 2011). Further, their attraction to power has also been shown to bring about follower perceptions of narcissists as emergent leaders, beyond the effects of extraversion (Brunell et al., 2008). There is thus evidence that positive perceptions of 
narcissists in zero-acquaintance situations increase the likelihood of narcissists being regarded as emergent leaders. However, with increasing acquaintance, others view narcissists less favorably because narcissists are more arrogant, less entertaining, tend to brag, and overestimate their abilities (Paulhus, 1998). This temporal change highlights the importance and influence of acquaintance level on the temporal perceptions toward narcissistic leadership; whereby individuals higher in narcissism are deemed positively as leaders by newly-acquainted others, but less so by well-acquainted others. Consequently, since acquaintance is developed through accumulated interpersonal interactions over time, the variant findings between short- and long-term acquaintance suggests that temporality may be responsible for differences in perceptions of narcissistic leadership. As such, temporality of leadership is central to understanding the dynamics of the relationship between narcissism and leadership - an understanding that is currently plagued with inconsistency in the literature.

The nature of the narcissism-leadership relationship over time is compounded by the reciprocal influence that both the leader and the follower can have on the leader-follower relationship (e.g., Howell \& Shamir, 2005). Although self-regulatory models of narcissism have allowed researchers to understand leadership through the lens of a narcissist, these models fail to account for the perspective of the follower and the potential temporal impact on the leader-follower relationship. As such, it is important to consider theoretical models (e.g., chocolate cake model) that might complement such self-regulatory models by providing a focus on the perceptions of those who are engaged in relationships with narcissists. Such a consideration would allow us to understand how changing contexts over time might lead to different perceptions of narcissistic leaders (Campbell \& Campbell, 2009).

Despite the theoretical advances that have been made regarding the dynamic relationship between narcissism and leadership, there is a dearth of evidence supporting this 
theorizing. The closest empirical evidence for the temporal nature of the narcissismleadership relationship comes from research focusing on the social cost of narcissists' decision-making strategies (Campbell, Bush, Brunell, \& Shelton, 2005). Campbell et al. demonstrated that narcissists' decision-making strategies focused on short-term gains at the expense of long-term benefits. Although these findings are somewhat supportive of narcissists' better performance in the short-term compared to the long-term, the decisionmaking paradigm does not integrate the social-interactional nature of leadership and thus cannot shed light on the temporal effectiveness of narcissistic leaders. It is this relative temporal effectiveness that is the focus of the present studies.

\section{Transformational leadership as a mechanism}

There is likely a complex interplay between narcissism and leadership across time, and the specific mechanism via which the temporality of this relationship might unfold remains unclear. One likely explanation is that the specific changes in narcissists' leader behaviors evolve over the course of leadership. Specifically, transformational leadership might explain why narcissistic individuals are perceived initially as leaders and why such positive perceptions might wane over time. Transformational leadership is an approach to leadership that involves establishing relationships with followers through personal, emotional and inspirational exchanges, so that followers are motivated to perform beyond their expectations (Bass, 1985). Additionally, transformational leader behaviors are associated with a myriad of positive outcomes, including: leader effectiveness, leader and/or group performance, satisfaction with the leader, follower motivation, and job satisfaction (see Judge \& Piccolo, 2004). Indeed, the charismatic and visionary components of transformational leadership, which are positively linked with narcissism (Deluga, 1997; Khoo \& Burch, 2008), will likely result in narcissists being initially perceived as effective leaders (Rosenthal \& 
Pittinsky, 2006). Thus, followers' perceptions of narcissistic leaders' effectiveness could be explained by narcissists' exhibition of transformational leadership behaviors.

The outcomes manifested through transformational leadership are also likely susceptible to the influence of time. For example, the positive impact of an inspirational speech given by a transformational leader might be short-lived unless its underlying vision is consistently reinforced by the leader's actions over time, and unless the leader expresses belief in the followers' ability to achieve that vision (see Shamir, 2011). Narcissists' ability to articulate a vision could influence followers to perceive them as transformational at the initial stage of leadership. However, given narcissists' continual striving for self-enhancement and personal glory to the extent of exploiting others for personal gain (e.g., Campbell et al., 2005; Jones, Woodman, \& Barlow, 2014), their transformational leadership behaviors are likely to fade over time. Consequently, it is likely that transformational leadership will mediate the relationship between narcissism and leadership effectiveness early during leadership, but not later. Specifically, the temporal reduction in this mediating effect is likely to be attributable to narcissists' diminishing display of transformational behaviors rather than any change in the well-established relationship between transformational leadership and leader effectiveness (Judge \& Piccolo, 2004).

\section{Present research}

The aim of the present research was twofold: (a) To test the hypothesis that individuals higher in narcissism will initially be perceived as leaders but that this perception will wane over time; and (b) to examine the mediating role of transformational leadership in the temporal perception of leaders who are higher in narcissism. We tested these predictions across two longitudinal studies utilizing unacquainted groups in Study 1 and acquainted groups in Study 2. In Study 1, we hypothesized that individuals rated higher in narcissism would initially be perceived as leaders, but not beyond the initial group formation phase. In 
Study 2, we explored these hypotheses with acquainted groups, and specifically the hypothesis that narcissistic leadership would eventually be perceived as negative by followers. With respect to the mediating role of transformational leadership, we hypothesized that transformational leadership would mediate the narcissism-leadership relationship initially but not over time.

\section{Study 1}

\section{Method}

Participants. We recruited 142 freshmen students as part of a psychology module in their first week in university. The timing of this choice of participants maximized the likelihood of group members meeting for the first time or at least having minimal acquaintance with each other. After accounting for participant dropout, 112 participants (71 men and 41 women; $M_{\text {age }}=19.0$ years; $S D=1.81$ ) were randomly assigned to 24 leaderless groups of between four and six members $(M=4.67$ members; $S D=0.64)$ and remained in the same groups throughout the study. A priori leader and follower roles were not assigned, thus enabling participants to develop and/or display leader behaviors during the group tasks (cf. Judge et al., 2002). Institutional ethical approval was obtained prior to the commencement of the study.

\section{Measures}

Narcissism. We assessed narcissism using the self-report Narcissism Personality Inventory (NPI; Raskin \& Hall, 1979; Raskin \& Terry, 1988). The NPI comprises 40 pairs of forced-choice statements where participants are asked to select the statement that best describes them. For each pair of statements, participants decide between a narcissistic statement (e.g., "I am an extraordinary person") and a non-narcissistic statement (e.g., "I am much like everybody else"). One point is scored for each narcissistic statement that is selected from each pair of statements. Following Brunell et al. (2008) we removed three pairs 
of statements that assess leadership (e.g., "I see myself as a good leader") from the final NPI scores in order to minimize the incidence of common method variance (cf. Podsakoff, MacKenzie, Lee, \& Podsakoff, 2003).

Leadership. We assessed peer ratings of leadership using Brunell et al.’s (2008) leadership measure, which assesses the extent to which each group member serves as a leader for a group task (e.g., "Group member X assumed a leadership role in the group"). Responses to the six items were rated on a seven-point scale ranging from 1 (very inaccurate) to 7 (very accurate).

Transformational leadership. We assessed peer ratings of transformational leadership using an adapted 10-item scale from the Multifactor Leadership Questionnaire (MLQ; Bass \& Avolio, 2005). This adapted scale has been previously used by Barling, Loughin, and Kelloway (2002), who selected two items from each of the four components of transformational leadership (idealized influence, inspirational motivation, individual consideration, and intellectual consideration) and from contingent reward. Although contingent reward is considered a transactional behavior, it was included because it has previously loaded consistently with the four transformational leadership components (Barling et al., 2002; Carless, 1998), and correlated highly with the dimensions of transformational leadership (.68 - .77, see Avolio, Bass, \& Jung, 1999). Additionally, an exploratory factor analysis with varimax rotation conducted by Barling et al. (2002) supported a single-factor structure that accounted for $55.5 \%$ of variance. Similar exploratory factor analyses performed on the present data also consistently supported a single-factor structure that accounted for between $46.6 \%$ and $82.9 \%$ variance for peer-rated transformational leadership. Responses to the items were rated on a five-point scale ranging from 0 (not at all) to 4 (frequently if not always). 
Procedure. The study was incorporated into a 12-week course as an experiential learning component of the course where students were asked to complete weekly group tasks in exchange for points. Feedback on group performance was presented in a league table at the beginning of each weekly lecture. The groups competed against each other for points and we told participants that the top three groups at the end of the study would win cash prizes of $£ 50, £ 30, £ 20$, respectively.

In the first week, we briefed participants that the study required them to work in groups to compete for points against other groups, gave assurances of confidentiality, and explained their right to withdraw from the study. After providing consent, participants completed a questionnaire pack that included narcissism and demographic questions.

In the second week, the participants engaged in their first group task. The groups completed a total of seven weekly tasks throughout the course, each lasting five minutes. The weekly tasks that were completed by the groups were common general knowledge tasks, such as naming all the medalists of Team Great Britain at the London 2012 Olympics, identifying the states of the USA on a blank map, and problem solving activities such as number puzzles. ${ }^{2}$ After completing the first group task in Week 2, participants appraised their group members' leadership. These round-robin peer leadership and transformational leadership evaluations were completed again after the group tasks in Weeks 4, 8 and 11. In Week 12, the final results were announced and the top three groups were awarded the cash prizes.

\section{Data analysis}

Round-robin peer ratings. Due to the round-robin nature of the study, we applied the Social Relations Model (Kenny, 1994) to the peer ratings for leadership and transformational leadership. The social relations model takes into account the interdependent nature of dyadic and intergroup perceptions, and segregates the peer ratings into perceiver, target, and relationship effects. In this study, we only extracted target effects, because these are 
independent of perceiver and relationship biases and we were only interested in the extent of group agreement on the leadership of a given target (see Kenny, 1994). Estimates of target effects were derived using the TripleR package (Schönbrodt, Back, \& Schmukle, 2012; see Gebauer, Sedikides, Verplanken, \& Maio, 2012 for a similar approach) operating on R (R Core Team, 2013), while accounting for the multiple groups.

Multilevel modeling. Given the nested nature of the data of participants within groups, and participants' leadership target effects being estimated at each time point, multilevel modeling was used to test the hypothesis that the narcissism-leadership relationship would change across time. Since the effect at each time point was of interest, we subjected the data to a multilevel multivariate response model. The proposed model comprised three hierarchical levels: time at Level 1, individuals at Level 2, and groups at Level 3. All analyses were tested using MLwiN via the iterative generalized least squares (IGLS) function (V.2.25; Rasbash, Browne, Healy, Cameron, \& Charlton, 2012).

Before conducting multilevel analyses, we standardized narcissism scores within each sex to control for sex differences (cf. Tchanz, Morf, \& Turner, 1998). All variables were also group mean centered. We used group mean centering rather than grand mean centering because it enabled us to analyze the relationships at the individual level by removing the influence of group (Enders \& Tofighi, 2007). As we aimed to investigate the effects of narcissism at the individual level on the outcome variable across time, the removal of between group variance through group mean centering before analysis was appropriate. We employed group mean centering for all leadership target effects when accounting for groups in TripleR, and for narcissism in MLwiN.

Multilevel mediation. We tested the hypothesized mediating role of transformational leadership on the narcissism-leadership relationship with multilevel mediation analyses. We calculated the indirect effect of the $a$ (narcissism predicting transformational leadership) and 
$b$ (transformational leadership predicting leadership) paths (cf. Bauer, Preacher, \& Gil, 2006) and subsequently tested this effect with the Monte Carlo Method for Assessing Mediation (MCMAM; Bauer et al., 2006; MacKinnon, Lockwood, \& Williams, 2004) calculator developed by Selig and Preacher (2008). The MCMAM calculator was specified at $95 \%$ confidence interval and 20,000 repetitions.

\section{Results}

Descriptive statistics and correlations for all the variables are presented in Table 1. Although the correlations provide some indication of the associations between narcissism and peer leadership perceptions, they are not indicative of possible relationships that arise from group membership, which warrants a multilevel approach. Initial inspection of the multilevel model revealed a non-significant reduction in the -2loglikelihood statistic when the random slopes model was specified over the random intercepts model. Consequently, the random intercepts model was adopted because allowing Level 3 slopes to vary did not significantly improve the model. As expected, ICCs derived from the basic model for leadership target effects were .00 across all time points since group level variance has already been accounted for in the a priori round-robin analyses ${ }^{3}$. However, a three-level model was still specified because narcissism could relate differentially to leadership within each group. The main effect of narcissism on leadership target effects was positive and significant at Time $1\left(\beta_{0}=\right.$ $.18, S E=.08, p=.02)$, but non-significant at Time $2\left(\beta_{1}=.10, S E=.06, p=.11\right)$, Time $3\left(\beta_{2}\right.$ $=.11, S E=.08, p=.18)$ and Time $4\left(\beta_{3}=.11, S E=.07, p=.12\right)$.

Mediation analysis. The hypothesis that transformational leadership would mediate the relationship between narcissism and leadership initially but not later was tested using multilevel mediation analysis. As recommended by Bauer et al. (2006) the simple product term $a * b$ was used to quantify the indirect effect. Multilevel mediation analyses revealed significant indirect effects at Time $1\left(\beta_{a}=.10, S E=.04, p=.01 ; \beta_{b}=1.82, S E=.13, p=.00\right.$; 
indirect effect $95 \% \mathrm{CI}[.05, .31])$ and Time $2\left(\beta_{a}=.09, S E=.04, p=.01 ; \beta_{b}=1.63, S E=.14\right.$, $p=.00$; indirect effect $[.03, .26])$ but not at Time $3\left(\beta_{a}=.01, S E=.04, p=.69 ; \beta_{b}=1.19, S E\right.$ $=.25, p=.00$; indirect effect $[-.07, .10])$ or Time $4\left(\beta_{a}=.04, S E=.05, p=.35 ; \beta_{b}=.85, S E=\right.$ $.15, p=.00$; indirect effect $[-.04, .12])$. Despite significant indirect effects only being evident at Time 1 and Time 2, it is noteworthy that the $b$ paths (transformational leadership predicting leadership) were significant and positive at each time point.

\section{Discussion}

Individuals rated higher in narcissism were initially perceived as leaders, but these perceptions disappeared over time; this finding was as hypothesized and is consistent with the chocolate cake model. Transformational leadership significantly mediated the relationship between narcissism and leadership early on but this mediating effect also dissipated over time. This dissipation was largely a specific reflection of the dissipation of the narcissism transformational leadership relationship. Indeed, the effect of transformational leadership on leadership remained consistently positive across each of the four time points. This finding is informative because it supports previous research that has revealed a strong association between transformational leadership behaviors and effective leadership (see Judge \& Piccolo, 2004) and suggests that the leadership decline of individuals higher in narcissism is associated with a relative decline in the degree to which they display transformational leadership behaviors.

By utilizing unacquainted groups in this study, we minimized prior knowledge of a person's narcissistic qualities, thereby maximizing the likelihood of achieving a zeroacquaintance environment for leader emergence. The initial positive perceptions of narcissistic leadership in unacquainted groups - and not when the groups become more acquainted - is consistent with previous research, which has revealed that narcissists are viewed more positively by new acquaintances than by close others (Back et al., 2010; Carlson 
et al., 2011; Paulhus, 1998). Nonetheless, our 12-week protocol does not allow us to extrapolate any inferences beyond the emergent phase of leadership in unacquainted groups. That is, although we have established that unacquainted groups soon tire of leaders who display narcissistic traits, we remain somewhat in the dark with regard to the emergent phase of leadership among acquainted groups. For example, after a longer period of acquaintance one would expect that the groups would not only have tired of many of the narcissistic leadership traits but would actively see these narcissistic traits as detrimental to effective leadership. Thus, in order to test the robustness of our hypotheses and to explore narcissismleadership effects beyond the initial unacquainted phase, in Study 2, we used acquainted group members. The use of acquainted groups increases the likelihood of group members having prior knowledge of narcissistic group members' leadership qualities, or lack thereof. Such a protocol allows for the examination of leadership perceptions in an acquainted phase that is beyond the more artificially derived (but yet untainted by acquaintance) leader emergence phase of Study 1.

\section{Study 2}

\section{Method}

Participants. We recruited 152 students (95 men, 56 women, 1 unreported) from psychology modules ${ }^{4}$ in junior and senior years. The participants were self-assigned to 29 groups each comprising four to six members $(M=5.24$ members; $S D=0.58)$ and remained in the same groups throughout the study. As in Study 1 a priori leader and follower roles were not assigned. Institutional ethical approval was obtained prior to the commencement of the study.

\section{Measures}

Narcissism, leadership and transformational leadership. These were measured and derived in the same way as in Study 1. Exploratory factor analyses of the transformational 
leadership scale supported a single-factor structure that accounted for between $37.5 \%$ and 73.3\% variance for peer-rated transformational leadership.

Procedure. The procedure was the same as in Study 1. Participants completed roundrobin peer leadership and transformational leadership evaluations at two time points: at Time 1 - after the first group task (Week 2), and at Time 2 - after the last group task (Week 11).

Data analysis. We used the same round-robin and multilevel analyses as in Study 1.

\section{Results}

Descriptive statistics and correlations for all the variables are presented in Table 2. We tested the hypothesis that individuals rated higher in narcissism would eventually be negatively perceived as leaders using multilevel analysis. Initial model inspection revealed a non-significant reduction in the -2loglikelihood statistic when the random slopes model was specified over the random intercepts model. Consequently, we used a random intercepts model. The main effects of narcissism on leadership target effects were non-significant at Time $1\left(\beta_{2}=-.03, S E=.04, p=.43\right)$ and significantly negative at Time $2\left(\beta_{3}=-.09, S E=.05\right.$, $p=.049)$.

Mediation analysis. As with Study 1 , the simple product term $a * b$ was used to quantify the indirect effect. Multilevel mediation analyses with transformational leadership target effects as a mediator revealed non-significant indirect effects for Time $1\left(\beta_{a}=-.03, S E\right.$ $=.04, p=.39 ; \beta_{b}=.61, S E=.12, p=.00$; indirect effect 95\% CI $\left.[-.07, .03]\right)$ and Time $2\left(\beta_{a}=\right.$ $-.02, S E=.05, p=.73 ; \beta_{b}=.28, S E=.09, p=.00$; indirect effect $\left.[-.04, .02]\right)$. Despite no significant indirect effects, the $b$ path (transformational leadership predicting leadership) was consistently significant and positive.

\section{Discussion}

The finding that individuals rated higher in narcissism were not perceived as leaders initially and were negatively perceived as leaders later on is consistent with the hypothesis 
within the chocolate cake model framework. Transformational leadership did not mediate the relationship between narcissism and leadership at either time point, as hypothesized. The effect of transformational leadership on leadership remained positive and significant across both time points, which is consistent with the findings from Study 1. This consistent positive effect observed between transformational leadership and leadership further supports the notion that the temporal perceptions of individuals higher in narcissism as leaders are dependent on the degree to which they display transformational behaviors.

In the acquainted groups of Study 2, in contrast to the unacquainted groups of Study 1, there was no honeymoon period and the individuals higher in narcissism were eventually perceived negatively. Previous research has shown that narcissists are viewed less positively by close others than by new acquaintances (Back et al., 2010; Carlson et al., 2011; Paulhus, 1998) - an effect that is strengthened by the present temporal design. The contextual difference between acquainted and unacquainted groups supports our earlier suggestion that perceptions of narcissistic leadership in more temporally advanced contexts are different from those perceptions where leadership is still in its infancy.

\section{General Discussion}

The purpose of the present research was twofold: (a) to test the hypothesis that individuals rated higher in narcissism would be perceived as leaders early on before losing such favor over time, and (b) to examine the mediating role of transformational leadership on the narcissism-leadership relationship across time.

We examined the temporality of narcissistic leadership via longitudinal investigations of groups comprising unacquainted and acquainted members in Studies 1 and 2, respectively. This approach enabled us to investigate narcissistic leadership during initial unacquainted group formation and in the more acquainted and established temporal phases of leadership. The findings in Study 1 revealed that individuals higher in narcissism were perceived as 
leaders by unacquainted group members initially but not later on. In Study 2 we found that acquainted group members did not rate individuals higher in narcissism as leaders and later rated narcissism as a negative leadership trait. Taken together, the findings of the two studies are consistent with the chocolate cake model (Campbell, 2005; Campbell et al., 2011) and demonstrate that initial positive peer perceptions of narcissistic leadership fade over time, and eventually become negative.

The peer-rated effects from both studies also complement previous predictions that individuals who possess the qualities that are suitable for leader emergence do not necessarily possess the qualities for leader effectiveness (Hogan et al., 1994; Rosenthal \& Pittinsky, 2006). Indeed, it has been suggested that narcissists' excellent social skills act as a buffer for their more undesirable traits that are geared toward agentic self-enhancement (Hogan \& Hogan, 2001). Thus, the observed peer-rated effects are consistent with theoretical predictions of how narcissists would fare as leaders over time, both from a self-regulatory and follower perspective.

Across the two studies we also examined whether transformational leadership could explain why narcissistic leadership wanes over time. In Study 1, transformational leadership in unacquainted groups mediated the relationship between narcissism and leadership initially, but not later. In Study 2, with more acquainted groups, transformational leadership was not a meaningful mediator of the narcissism-leadership relationship. It is noteworthy that a consistent significant positive relationship between transformational leadership and leadership was revealed across all time points across both studies. This consistent relationship further supports the beneficial effects of transformational leadership on leader effectiveness (Judge \& Piccolo, 2004). Specifically in the context of narcissistic leadership, the degree to which individuals higher in narcissism are viewed as leaders over time will likely be 
dependent on how capable they are of displaying the requisite transformational behaviors within their group.

Beyond the initial stage of leadership, positive follower perceptions of narcissistic leadership could gradually be damaged by the perceived lack of transformational leadership behaviors on offer, as individuals higher in narcissism are more likely to display behaviors that serve their drive for self-enhancement. In the initial stage of leadership, however, it is likely that individuals higher in narcissism have the ability to portray visionary aspects of transformational leadership making them attractive as leaders (Khoo \& Burch, 2004; Rosenthal \& Pittinsky, 2006). Indeed, followers find visionary leaders more appealing than representative leaders who focus on their group's collective identity (Halevy, Berson, \& Galinsky, 2011). Besides vision, transformational leadership also comprises strong support and challenge components (Arthur, Hardy \& Woodman, 2012; Hardy et al., 2010), both of which could be particularly crucial beyond the initial stage of leadership. For example, individual consideration is a support component of transformational leadership and narcissists' relative lack of individual consideration (Khoo \& Burch, 2008) may well contribute to the eventual decay of their leadership effectiveness.

Individuals rated higher in narcissism might also be positively perceived as leaders during the initial stage of leadership by virtue of being placed in a context that is optimal for them to emerge as leaders. Being randomly assigned to groups with unacquainted group members in Study 1 inadvertently created a more uncertain social context (relative to the acquainted group context of Study 2) in which narcissistic leadership can thrive. Indeed, narcissists are more likely to be chosen as leaders in uncertain contexts, despite followers being aware of their undesirable traits (Nevicka, De Hoogh, Van Vianen, \& Ten Velden, 2013), and are considered effective leaders even when performance suggests otherwise (Nevicka, Ten Velden, et al., 2011). 


\section{Future research and applied implications}

The present data suggest that it is the ability of individuals with narcissistic traits to display transformational leadership behaviors that enables them to be perceived as leaders early on. Transformational leadership involves the establishment of emotional relationships between leader and follower, which could be particularly impactful beyond the initial stage of leadership. One emotional aspect that could be useful for leadership beyond the initial stage and one that narcissists are theorized to lack - is empathy (e.g., Watson \& Morris, 1991). Empathy has been positively linked with leadership (Kellett, Humphrey, \& Sleeth, 2006) and has been shown to impact group cohesion (Van Vugt \& Schaller, 2008). If narcissistic leaders have the capacity to become more empathic toward their followers then perhaps the durability of the follower satisfaction in their leadership might increase. Empathy is considered a multidimensional construct that involves cognitive and affective components (Vreeke \& van der Mark, 2003). Cognitive empathy is the ability to discern the emotional states of others without undergoing emotional contagion, while affective empathy is an observer's emotional response to the affective state of others (Davis, 1983). Contrary to reports that narcissists lack empathy, narcissists have been found to be capable of cognitive empathy, although they lack affective empathy (Wai \& Tiliopoulos, 2012). Furthermore, perspective-taking has been shown to increase narcissists' empathy (Hepper, Hart, \& Sedikides, 2014). This leads to the intriguing prospect that narcissists who are capable of displaying empathic behaviors, and who understand the importance of displaying such behaviors, might enjoy a longer period of follower-endorsed leadership.

Narcissists are attracted to leadership because it is perceived as an opportunity for self-enhancement (Campbell \& Campbell, 2009). Evidently, an element of self-enhancement appears critical to motivate narcissists to act upon something. Drawing from previous research on task persistence (Wallace, Ready, \& Weitenhagen, 2009), it seems that narcissists 
are more likely to persist in their leadership roles only to the degree that competing opportunities for self-enhancement are absent. Such persistence might be hard to enact in reality, however. Indeed, narcissists are less likely to delay gratification (Vazire \& Funder, 2006) and more likely to take advantage of more immediate opportunities for selfenhancement over more complex self-enhancing opportunities (Wallace et al., 2009). This fixation on instant self-enhancement suggests that narcissists can be effective leaders provided that they are constantly focused on short-term self-enhancing goals. Additionally, when working in groups, narcissists perform better as leaders by engaging in more non-verbal communication and team assistance under the context of high reward interdependence (Nevicka, De Hoogh, et al., 2011), which suggests that narcissists can be drawn toward selfenhancement through the achievement of group goals. Consequently, organizations can encourage narcissists to be more effective leaders over time by structuring more selfenhancing short-term leadership goals that are highly interdependent. For example, traditional annual work reviews can be restructured into regular monthly reviews where narcissists' leadership performance is judged by team feedback and performance.

Although the decline of initial positive peer perceptions of leadership appears characteristic of narcissistic leaders, Boal and Hooijberg (2000) proposed that such a temporal pattern of leadership is rather more universal. Termed the "honeymoon effect", this temporal decline is thought to be caused by leadership stagnation that could emerge from overconfidence, homogeneity, or complacency (Giambatista, 2004). Narcissistic leaders might suffer from the honeymoon aftermath much like any leader displaying the aforementioned traits, since leader training and selection criteria in general seem to promote narcissistic characteristics that are favorable toward leader emergence in the first place (Campbell et al., 2011). Thus, an overemphasis on the qualities that promote leader emergence not only suits narcissists but could also lead to a higher concentration of 
narcissists in leadership positions, and paradoxically less effective leadership. Future research would benefit from exploring how individuals higher in narcissism perform in leadership selection processes that focus on aspects that are important for leadership effectiveness rather than leadership emergence, and whether these processes can be incorporated within current practices in leadership recruitment. Such a leadership recruitment awareness and focus would stand to increase the likelihood of selecting "temporally resilient" leadership and enhance organizational stability. Put simply, the leader that looks good at first may be precisely the leader to avoid for the long-term.

\section{Limitations}

The main limitation of the present research is its external validity because of the exclusive use of students. However, this population afforded an excellent naturalized environment to test the hypotheses, and we were able to utilize samples at varying degrees of acquaintance to explore effects over an extended period. Such a stable environment might not be so easily achievable in other organizational settings. A second limitation of the studies was the lack of consideration of group performance. This concern is rather modest, however, because performance scores were used as a motivator for continued engagement across the timeline, which was important in allowing leadership to be continually relevant across time. In other words, performance was not conceptualized as a dependent variable. Nonetheless, given that organizational performance is volatile when fronted by narcissistic leaders (Chatterjee \& Hambrick, 2007), temporal investigations of team performance appear worthy of research attention. A third limitation of the present research was its quasi-longitudinal design, which enabled us to examine different temporal phases of leadership, but not with the same sample of participants. The two time-point design employed in Study 2 was also experimentally weaker relative to the four time-point design used in Study 1. A repeated 
measures design that presents a consistent investigation of narcissistic leadership over an extended temporal phase would be an interesting extension of the present research.

\section{Conclusion}

Individuals higher in narcissism are initially perceived as leaders in unacquainted leaderless groups. They do not enjoy these positive perceptions for long, however, and eventually suffer a decline toward negative perceptions from their followers. The initial positive perception of individuals higher in narcissism as leaders is mediated by their display of appropriate transformational leadership behaviors such that their effectiveness is largely dependent on how transformational they are perceived to behave. 


\section{Declaration of Conflicting Interests}

The authors declared no potential conflicts of interest with respect to the research, authorship, and/or publication of this article.

\section{Funding}

The authors received no financial support for the research, authorship, and/or publication of this article. 


\section{References}

Albright, L., Kenny, D. A., \& Malloy, T. E. (1988). Consensus in personality judgments at zero acquaintance. Journal of Personality \& Social Psychology, 55, 387-395. doi: $10.1037 / 0022-3514.55 .3 .387$

Arthur, C. A., Hardy, L., \& Woodman, T. (2012). Realising the Olympic dream: vision, support and challenge. Reflective Practice, 13, 399-406. doi: $10.1080 / 14623943.2012 .670112$

Avolio, B. J., Bass, B. M., \& Jung, D. I. (1999). Re-examining the components of transformational and transactional leadership using the Multifactor Leadership Questionnaire. Journal of Occupational and Organizational Psychology, 72, 441462. doi: $10.1348 / 096317999166789$

Back, M. D., Schmukle, S. C., \& Egloff, B. (2010). Why are narcissists so charming at first sight? Decoding the narcissism-popularity link at zero acquaintance. Journal of Personality \& Social Psychology, 98, 132-145. doi: 10.1037/a0016338

Barling, J., Loughlin, C., \& Kelloway, K. E. (2002). Development and test of a model linking safety-specific transformational leadership and occupational safety. Journal of Applied Psychology, 87, 488-496. doi: 10.1037//0021-9010.87.3.488

Bass, B. M. (1985). Leadership and performance beyond expectations. New York: Free Press.

Bass, B. M., \& Avolio, B. J. (2005). MLQ: Multifactor Leadership Questionnaire (2 $2^{\text {nd }}$ ed.). Redwood City, CA: Mind Garden.

Bauer, D. J., Preacher, K. J., \& Gil, K. M. (2006). Conceptualizing and testing random indirect effects and moderated mediation in multilevel models: new procedures and recommendations. Psychological Methods, 11, 142-163. doi: 10.1037/1082989X.11.2.142 
Blair, C. A., Hoffman, B. J., \& Helland, K. R. (2008). Narcissism in organizations: A multisource appraisal reflects different perspectives. Human Performance, 21, 254276. doi: 10.1080/08959280802137705

Bluedorn, A., \& Jaussi, K. (2008). Leaders, followers, and time. The Leadership Quarterly, 19, 654-668. doi: 10.1016/j.leaqua.2008.09.006

Boal, K. B., \& Hooijberg, R. (2000). Strategic leadership research: Moving on. The Leadership Quarterly, 11, 515-549. doi: 10.1016/S1048-9843(00)00057-6

Bradlee, P. M. \& Emmons, R. A. (1992). Locating narcissism within the interpersonal circumplex and the five-factor model. Personality and Individual Differences, 13, 821-830. doi: 10.1016/0191-8869(92)90056-U

Brunell, A. B., Gentry, W. A, Campbell, W. K., Hoffman, B. J., Kuhnert, K. W., \& Demarree, K. G. (2008). Leader emergence: the case of the narcissistic leader. Personality and Social Psychology Bulletin, 34, 1663-1676. doi: $10.1177 / 0146167208324101$

Campbell, W. K. (2005). When you love a man who loves himself: How to deal with a oneway relationship. Chicago: Sourcebooks Casablanca.

Campbell, W. K., Brunell, A. B., \& Finkel, E. J. (2006). Narcissism, interpersonal selfregulation, and romantic relationships: An agency model approach. In K. D. Vohs \& E. J. Finkel (Eds.), Self and relationships: Connecting intrapersonal and interpersonal processes (pp. 57-83). New York, NY, US: Guildford Press.

Campbell, W. K., Bush, C. P., Brunell, A. B., \& Shelton, J. (2005). Understanding the social costs of narcissism: the case of the tragedy of the commons. Personality and Social Psychology Bulletin, 31, 1358-68. doi: 10.1177/0146167205274855

Campbell, W. K., \& Campbell, S. M. (2009). On the self-regulatory dynamics created by the peculiar benefits and costs of narcissism: A contextual reinforcement model and 
examination of leadership. Self and Identity, 8, 214-232. doi:

$10.1080 / 15298860802505129$

Campbell, W. K., Hoffman, B. J., Campbell, S. M., \& Marchisio, G. (2011). Narcissism in organizational contexts. Human Resource Management Review, 21, 268-284. doi: 10.1016/j.hrmr.2010.10.007

Carless, S. A. (1998). Assessing the discriminant validity of transformational leadership behavior as measured by the MLQ. Journal of Occupational and Organizational Psychology, 71, 353-358. doi: 10.1111/j.2044-8325.1998.tb00681.x

Carlson, E. N., Vazire, S., \& Oltmanns, T. F. (2011). You probably think this paper's about you: Narcissists' perceptions of their personality and reputation. Journal of Personality \& Social Psychology, 101, 185-201. doi: 10.1037/a0023781

Chatterjee, A., \& Hambrick, D. C. (2007). It's all about me: Narcissistic chief executive officers and their effects on company strategy and performance. Administrative Science Quarterly, 52, 351-386. doi: 10.2189/asqu.52.3.351

Dansereau, F., Jr., Yammarino, F. J., Markham, S. E., Allutto, J. A., Newman, J., Dumas, M., ... Keller, T. (1995). Individualized leadership: A new multiple-level approach. The Leadership Quarterly, 6, 413-450. doi: 10.1016/1048-9843(95)90016-0

Davis, M. H. (1983). Measuring individual differences in empathy: Evidence for a multidimensional approach. Journal of Personality \& Social Psychology, 44, 113126. doi: 10.1037/0022-3514.44.1.113

Deluga, R. J. (1997). Relationship among American presidential charismatic leadership, narcissism, and rated performance. The Leadership Quarterly, 8, 49-65. doi: 10.1016/S1048-9843(97)90030-8 
Enders, C. K., \& Tofighi, D. (2007). Centering predictor variables in cross-sectional multilevel models: a new look at an old issue. Psychological Methods, 12, 121-138. doi: 10.1037/1082-989X.12.2.121

Foti, R. J., Knee, R. E., Jr., \& Backert, R. S. G. (2008). Multiple level implications of frame leadership perceptions as a dynamic process. The Leadership Quarterly, 19, 178-194. doi: 10.1016/j.leaqua.2008.01.007

Gebauer, J. E., Sedikides, C., Verplanken, B., \& Maio, G. R. (2012). Communal narcissism. Journal of Personality \& Social Psychology, 103, 854-878. doi: 10.1037/a0029629

Giambatista, R. C. (2004). Jumping through hoops: A longitudinal study of leader life cycles in the NBA. The Leadership Quarterly, 15, 607-624. doi:

10.1016/j.leaqua.2004.07.002

Halevy, N., Berson, Y., \& Galinsky, A. D. (2011). The mainstream is not electable: When vision triumphs over representativeness in leader emergence and effectiveness. Personality and Social Psychology Bulletin, 37, 893-904. doi:

$10.1177 / 0146167211402836$

Hardy, L., Arthur, C. A., Jones, G., Shariff, A., Munnoch, K., Isaacs, I., \& Allsopp, A. J. (2010). The relationship between transformational leadership behaviors, psychological, and training outcomes in elite military recruits. The Leadership Quarterly, 21, 20-32. doi: 10.1016/j.leaqua.2009.10.002

Hepper, E. G., Hart, C. M., \& Sedikides, C. (2014). Moving narcissus: Can narcissists be empathic? Personality and Social Psychology Bulletin, 40, 1-13. doi: $10.1177 / 0146167214535812$

Hogan, R., Curphy, G. J., \& Hogan, J. (1994). What we know about leadership: Effectiveness and personality. American Psychologist, 49, 493-504. doi: 10.1037/0003066X.49.6.493 
Hogan, R., \& Hogan, J. (2001). Assessing leadership: A view from the dark side.

International Journal of Selection and Assessment, 9, 40-51. doi: 10.1111/14682389.00162

Hogan, R., \& Kaiser, R. B. (2005). What we know about leadership. Review of General Psychology, 9, 169-180. doi: 10.1037/1089-2680.9.2.169

Howell, J. M., \& Shamir, B. (2005). The role of followers in charismatic leadership:

Relationships and their consequences. Academy of Management Review, 2005, 96-112. doi: 10.5465/AMR.2005.15281435

Hox, J. J. (2010). Multilevel analysis: Techniques and applications. (2nd ed.). New York: Routledge.

Jones, B. D., Woodman, T., \& Barlow, M. (2014). Narcissism predicts moral disengagement and anti-social behaviour. Psychology of Sport and Exercise (under second review).

Judge, T. A., Bono, J. E., Ilies, R., \& Gerhardt, M. W. (2002). Personality and leadership: A qualitative and quantitative review. Journal of Applied Psychology, 87, 765-780. doi: 10.1037/0021-9010.87.4.765

Judge, T. A., LePine, J. A., \& Rich, B. L. (2006). Loving yourself abundantly: Relationship of the narcissistic personality to self- and other perceptions of workplace deviance, leadership, and task and contextual performance. Journal of Applied Psychology, 91, 762-776. doi: 10.1037/0021-9010.91.4.762

Judge, T. A., \& Piccolo, R. F. (2004). Transformational and transactional leadership: A metaanalytic test of their relative validity. The Journal of Applied Psychology, 89, 755-68. doi: $10.1037 / 0021-9010.89 .5 .755$

Kellett, J. B., Humphrey, R. H., \& Sleeth, R. G. (2006). Empathy and the emergence of task and relations leaders. The Leadership Quarterly, 17, 146-162. doi: 10.1016/j.leaqua.2005.12.003 
Kenny, D. (1994). Interpersonal perceptions: A social relations analysis. New York: Guildford Press.

Kenny, D. A., Horner, C., Kashy, D. A., \& Chu, L. (1992). Consensus at zero acquaintance: Replication, behavioral cues, and stability. Journal of Personality \& Social Psychology, 62, 88-97. doi: 10.1037/0022-3514.62.1.88

Khoo, H. S., \& Burch, G. S. J. (2008). The "dark" side of leadership personality and transformational leadership: an exploratory study. Personality and Individual Differences, 44, 86-97. doi: 10.1016/j.paid.2007.07.018

MacKinnon, D. P., Lockwood, C. M., \& Williams, J. (2004). Confidence limits for the indirect effect: Distribution of the product and resampling methods. Multivariate Behavioral Research, 39, 99-128. doi: 10.1207/s15327906mbr3901_4

Malloy, T. E., \& Albright, L. (1990). Interpersonal perception in a social context. Journal of Personality \& Social Psychology, 58, 419-428. doi: 10.1037/0022-3514.58.3.419

Miller, J. D., \& Campbell, W. K. (2011). Addressing criticisms of the Narcissistic Personality Inventory (NPI). In W. K. Campbell \& J. D. Miller (Eds.), Handbook of narcissism and narcissistic personality disorder: Theoretical approaches, empirical findings, and treatments (pp. 146-152). Hoboken, NJ: John Wiley \& Sons, Inc.

Morf, C. C., \& Rhodewalt, F. (2001). Unraveling the paradoxes of narcissism: A dynamic self-regulatory processing model. Psychological Inquiry, 12, 177-196. doi: 10.1207/S15327965PLI1204_1

Nevicka, B., De Hoogh, A. H. B., Van Vianen, A. E. M., Beersma, B., \& McIlwain, D. (2011). All I need is a stage to shine: Narcissists' leader emergence and performance. The Leadership Quarterly, 22, 910-925. doi: 10.1016/j.leaqua.2011.07.011 
Nevicka, B., De Hoogh, A. H. B., Van Vianen, A. E. M., \& Ten Velden, F. S. (2013), Uncertainty enhances the preference for narcissistic leaders. European Journal of Social Psychology, 43, 370-380. doi: 10.1002/ejsp.1943

Nevicka, B., Ten Velden, F. S., De Hoogh, A. H. B., \& Van Vianen, A. E. M. (2011). Reality at odds with perceptions: Narcissistic leaders and group performance. Psychological Science, 22, 1259-1264. doi: 10.1177/0956797611417259

Oltmanns, T. F., Friedman, J. N., Fiedler, E. R., \& Turkheimer, E. (2004). Perceptions of people with personality disorders based on thin slices of behavior. Journal of Research in Personality, 38, 216-229. doi: 10.1016/S0092-6566(03)00066-7

Paulhus, D. L. (1998). Interpersonal and intrapsychic adaptiveness of trait self-enhancement: A mixed blessing? Journal of Personality \& Social Psychology, 74, 1197-1208. doi: 10.1037/0022-3514.74.5.1197

Podsakoff, P. M., MacKenzie, S. B., Lee, J. Y., \& Podsakoff, N. P. (2003). Common method biases in behavioral research: A critical review of the literature and recommended remedies. Journal of Applied Psychology, 88, 879-903. doi: 10.1037/00219010.88 .5 .879

R Core Team. (2013). R: A language and environment for statistical computing. Vienna, Austria. Retrieved from http://www.R-project.org/.

Rasbash, J., Browne, W. J., Healy, M., Cameron, B., \& Charlton, C. (2012) MLwiN Version 2.25. Centre for Multilevel Modelling, University of Bristol.

Raskin, R., \& Hall, C. S. (1979). A narcissistic personality inventory. Psychological Reports, 45, 590. doi: 10.2466/pr0.1979.45.2.590

Raskin, R., \& Terry, H. (1988). A principal-components analysis of the Narcissistic Personality Inventory and further evidence of its construct validity. Journal of Personality \& Social Psychology, 54, 890-902. doi: 10.1037/0022-3514.54.5.890 
Roberts, R., Callow, N., Hardy, L., Woodman, T., \& Thomas, L. (2010). Interactive effects of different visual imagery perspectives and narcissism on motor performance. Journal of Sport \& Exercise Psychology, 32, 499-517.

Roberts, R., Woodman, T., Hardy, L., Davis, L., \& Wallace, H. M. (2013). Psychological skills do not always help performance: The moderating role of narcissism. Journal of Applied Sport Psychology, 25, 316-325. doi: 10.1080/10413200.2012.731472

Rosenthal, S., \& Pittinsky, T. (2006). Narcissistic leadership. The Leadership Quarterly, 17, 617-633. doi: 10.1016/j.leaqua.2006.10.005

Schönbrodt, F. D., Back, M. D., \& Schmukle, S. C. (2012). TripleR: An R package for social relations analyses based on round robin designs. Behavior Research Methods, 44, 455-470. doi: 10.3758/s13428-011-0150-4

Selig, J. P., \& Preacher, K. J. (2008, June). Monte Carlo method for assessing mediation: An interactive tool for creating confidence intervals for indirect effects [Computer software]. Retrieved from http://quantpsy.org/.

Shamir, B. (2011). Leadership takes time: Some implications of (not) taking time seriously in leadership research. The Leadership Quarterly, 22, 307-315. doi: 10.1016/j.leaqua.2011.02.006

Shamir, B., \& Howell, J. M. (1999). Organizational and contextual influences on the emergence and effectiveness of charismatic leadership. The Leadership Quarterly, 10, 257-283. doi: 10.1016/S1048-9843(99)00014-4

Tschanz, B. B., Morf, C. C., \& Turner, C. M. (1998). Gender differences in the structure of narcissism: A multi-sample analysis of the Narcissistic Personality Inventory. Sex Roles, 38, 863-870. doi: 10.1023/A:1018833400411

Van Vugt, M., \& Schaller, M. (2008). Evolutionary approaches to group dynamics: An introduction. Group Dynamics, 12, 1-6. doi: 10.1037/1089-2699.12.1.1 
Vazire, S., \& Funder, D. C. (2006). Impulsivity and the self-defeating behavior of narcissists. Personality and Social Psychology Review, 10, 154-165. doi: $10.1207 / \mathrm{s} 15327957$ pspr1002_4

Vreeke, G. J., \& van der Mark, I. L. (2003). Empathy: An integrative model. New Ideas in Psychology, 21, 177-207. doi: 10.1016/j.newideapsych.2003.09.003

Wai, M., \& Tiliopoulos, N. (2012). The affective and cognitive empathic nature of the dark triad of personality. Personality and Individual Differences, 52, 794-799. doi: 10.1016/j.paid.2012.01.008

Wallace, H. M., \& Baumeister, R. F. (2002). The performance of narcissists rises and falls with perceived opportunity for glory. Journal of Personality \& Social Psychology, 82, 819-834. doi: 10.1037/0022-3514.82.5.819

Wallace, H. M., Ready, C. B., \& Weitenhagen, E. (2009). Narcissism and Task Persistence. Self and Identity, 8, 78-93. doi: 10.1080/15298860802194346

Watson, P. J., \& Morris, R. J. (1991). Narcissism, empathy and social desirability. Personality and Individual Differences, 12, 575-579. doi: 10.1016/01918869(91)90253-8

Watts, A. L., Lilienfeld, S. O., Smith, S. F., Miller, J. D., Campbell, W. K., Waldman, I. D., ... Faschingbauer, T. J. (2013). The double-edged sword of grandiose narcissism: Implications for successful and unsuccessful leadership among U.S. presidents. Psychological Science, 24, 2379 -2389. doi: 10.1177/0956797613491970

Woodman, T., Roberts, R., Hardy, L., Callow, N., \& Rogers, C. H. (2011). There is an "I" in TEAM: Narcissism and social loafing. Research Quarterly for Exercise and Sport, 82, 285-290. doi: 10.1080/02701367.2011.10599756 


\section{Footnotes}

${ }^{1}$ The term "narcissist" has been commonly used in the literature (cf. Miller \& Campbell 2011; Wallace \& Baumeister, 2002) to refer to people scoring relatively higher on the Narcissistic Personality Inventory (NPI; Raskin \& Hall, 1979; Raskin \& Terry, 1988), which is a measure of sub-clinical narcissism (i.e., not the NPD variant of narcissism). Consequently, we have used the term "narcissist" only when referring to and discussing previous research on sub-clinical narcissism. In addition, narcissism in the context of the current research is defined by narcissistic grandiosity, which is in line with previous theorization of narcissistic leadership (e.g., Rosenthal \& Pittinsky, 2006).

${ }^{2}$ Details of the activities are available on request from the first author.

${ }^{3}$ ICCs derived for peer-rated leadership prior to accounting for group level effects were 0.00 at Time 1, 0.01 at Time 2, 0.33 at Time 3 and 0.05 at Time 4 in Study 1. In Study 2, the ICCs for peer-rated leadership prior to accounting for group level effects were 0.52 at Time 1 and 0.12 at Time 2. The ICCs were near zero at Time 1 and Time 2 in Study 1, which could be due to unacquainted groups being assigned at random (i.e., an indication that randomization was successful). Group differences are minimized if members are assigned randomly as observed in other studies that have used a similar small group zeroacquaintance paradigm, where substantive between group differences are absent (e.g., Albright, Kenny, \& Malloy, 1988; Kenny, Horner, Kashy, \& Chu, 1992; Malloy \& Albright, 1990). As group members become more acquainted across time, the effect of randomization is likely to wear out, resulting in more considerable group differences. Consequently, substantial group level effects were evident from the ICCs observed at Time 3 and Time 4 of Study 1. Furthermore, higher ICCs were also observed in Study 2, which utilized self-selected, acquainted groups.

\footnotetext{
${ }^{4}$ In British universities, it is typical for students in the same degree program to register for
} 
the same modules, which results in a core group of students with frequent opportunities to interact with each other during tutorials, group work, etc. The sample recruited in Study 2 comprised students who were in the second semester of their junior and senior years, and had been acquainted with each other for at least one and a half years. The participants recruited in Study 2 were not the same participants as in Study 1. 
Table 1

Means, standard deviations, and zero-order correlations between narcissism and peer-rated leadership perceptions in Study 1

\begin{tabular}{|c|c|c|c|c|c|c|c|c|c|c|c|c|}
\hline & & Mean & SD & 1 & 2 & 3 & 4 & 5 & 6 & 7 & 8 & 9 \\
\hline 1 & Narcissism & 13.72 & 6.77 & $(.85)$ & & & & & & & & \\
\hline 2 & Leadership Time 1 & 4.40 & 0.76 & .17 & $(.92)$ & & & & & & & \\
\hline 3 & Leadership Time 2 & 4.64 & 1.12 & .15 & $.39 * *$ & $(.93)$ & & & & & & \\
\hline 4 & Leadership Time 3 & 4.46 & 0.88 & .12 & .23 & $.61 * *$ & $(.90)$ & & & & & \\
\hline 5 & Leadership Time 4 & 4.47 & 0.87 & .08 & $.45^{* *}$ & $.68 * *$ & $.87 * *$ & $(.88)$ & & & & \\
\hline 6 & Transformational leadership Time 1 & 2.57 & 0.55 & $.22 *$ & $.82 * *$ & $.56 * *$ & $.47 *$ & $.44 * *$ & $(.91)$ & & & \\
\hline 7 & Transformational leadership Time 2 & 2.47 & 0.55 & .17 & $.52 * *$ & $.85 * *$ & $.54 * *$ & $.54 * *$ & $.64 * *$ & $(.93)$ & & \\
\hline 8 & Transformational leadership Time 3 & 2.47 & 0.63 & -.14 & .29 & $.46^{*}$ & $.64 * *$ & $.72 * *$ & .15 & $.51 * *$ & $(.94)$ & \\
\hline 9 & Transformational leadership Time 4 & 2.37 & 0.56 & .08 & .25 & $.62 * *$ & $.61 * *$ & $.75^{* *}$ & .27 & $.45^{*}$ & $51 * *$ & $(.92)$ \\
\hline
\end{tabular}

Note: The range of total score is 0-37 for narcissism; 1-7 for mean peer-rated leadership; and 0-4 for mean peer-rated transformational leadership. Cronbach $\alpha$ coefficients are presented in parentheses (nb. $\alpha$ s for leadership and transformational leadership were averaged across group members). Correlations are between narcissism and target effects of leadership and transformational leadership.

$* * p<.01 ; * p<.05$ 
Table 2

Means, standard deviations, and zero-order correlations between narcissism and peer-rated leadership perceptions in Study 2

\begin{tabular}{|c|c|c|c|c|c|c|c|c|}
\hline & & Mean & SD & 1 & 2 & 3 & 4 & 5 \\
\hline 1 & Narcissism & 13.90 & 7.31 & $(.87)$ & & & & \\
\hline 2 & Leadership Time 1 & 4.36 & 0.76 & .03 & $(.88)$ & & & \\
\hline 3 & Leadership Time 2 & 4.54 & 1.10 & -.19 & $.37 * *$ & $(.94)$ & & \\
\hline 4 & Transformational leadership Time 1 & 2.81 & 0.39 & -.08 & $.54 * *$ & .20 & $(.85)$ & \\
\hline 5 & Transformational leadership Time 2 & 3.63 & 2.74 & -.05 & .09 & $.24 * *$ & .10 & $(.94)$ \\
\hline
\end{tabular}

Note: The range of total score is 0-37 for narcissism; 1-7 for mean peer-rated leadership; and 0-4 for mean peer-rated

transformational leadership. Cronbach $\alpha$ coefficients are presented on the diagonal in parentheses (nb. $\alpha$ s for leadership and transformational leadership were averaged across group members). Correlations are between narcissism and target effects of leadership and transformational leadership.

$* * p<.01 ; * p<.05$. 